\title{
Prospective Study of Adult Onset Seizure
}

\author{
HP Paliwal ${ }^{1}$,Vinayak Kalla ${ }^{2}$,Diwanshu Khatana ${ }^{3}$, S Capoor $^{4}$ \\ Dept. Of General Medicine, Mahatma Gandhi Medical College \& Hospital, Sitapura, Jaipur, Rajasthan 302022
}

\begin{abstract}
Background: Seizures are paroxysmal events due to abnormal excessive neuronal activity of the brain manifesting in varying clinical spectrum of focal or generalized seizures. In adults onset seizures the etiologies could be CNS infections, CVA, metabolic-factors, brain tumors and many other factors. Thus the objective of this study was to elaborate various clinical types of adult onset seizures with various etiological factors specially in adult age group.

Material and methods: After obtaining ethical approval from institute committee, The participants were recruited from outdoor as well indoor services in department of medicine with onset of seizures at the age of 20 years and above. Total 100 cases were included in this study. The date ware collected on a specially designed proforma of multiple questionnaires with detailed physical examination and relevant investigations.

Results: There were total 100 cases (M 57, F 43) of adult onset seizures in this study. Majority of patients were with age group of 21-30 years (51\%) and with further advancing age the incidence of onset of seizures was in decreasing order. Out of total cases, the 69 (69\%) cases were of GTCS (M 42, F 27) and remaining cases of SPS, CPS, PSSG \& status epilepticus. $85 \%$ of all cases had some etiological factor \& $15 \%$ were of idiopathic group. Among etiologic groups the maximum cases were of neurological infections ( $n$ 36), CVA (n 23), metabolic case (n 7), tumor (n 5), OPC poisoning ((n 4), eclampsia (n 3) \& miscellaneous ( $n$ 7), The incidence of neuro infections was more in males while CVA's were more in females. The neuroimaging study was abnormal in 75 of the cases (65.22\% if cases of GTCS and 100\% of cases of focal seizures) while EEG was found abnormal $30.43 \%$ cases of GTCS while the overall abnormality was only in 35 cases (35\%).

Conclusion: with advanced neuroimaging technique the etiological factors could be detected in maximum number of cases to help in precise management \& better prognosis.
\end{abstract}

Keywords: SPS (simple partial seizures), CPS (complex partial seizures), CVA (cardiovascular accidents), SE (status epileptics), EEG (electro encephalo graphy), MRI (magnetic resonance imaging), OPC (organophosphate compound), PSSG (partial seizures with secondary general stations)

\section{Introduction}

The seizures are paroxysmal events due to abnormal excessive neuronal activities in the brain. The patients are belled epileptic when there is recurrence of two or more episodes of seizures. There are many forms and causes of epilepsy with distinct clinical and pathological characteristics. In childhood (early onset) seizures the idiopathic causes are common, however in adult onset seizures, the known etiological factors are common in the form of CNS infections, cerebro vascular accidents, brain tumor, metabolic disorders, post traumatic, alcohol withdrawal, drug toxicity and poisoning etc. in women, the eclampsia and post puerperal causes are also common. In this prospective study, detailed clinical neurological examination of all cases was carried out along with relevant laboratory investigations, EEG neurological imaging study and other investigations study and other investigations were carried out to classify the seizures and to find out etiological diagnosis which were of specific importance in adult population of more than 20 years of age with confirmed cases of seizures.

\section{Material and methods}

This observational study was performed in department of medicine of MGH (tertiary centre) Jaipur and 100 cases of adult onset seizures were included from OPD and indoor during a period of approx 2 years. Ethical approval was obtained from institutions research ethics committee written informed consent was taken from all subjects. Data were collected on a specially designed proforma having multiple questionnaires, describing base line demography. Detailed clinical examination and relevant laboratory testing neuro imaging, EEG etc. were carried out to find out the specific etiology.

\section{Observations and results}

The patients age ranged from 20 years to 76 years with mean age of 35.82 years. The majority of patients were in the age group of $21-30$ years (n 51, 51\%) followed by $17 \%$ in age group $41-50,31-40$ years $(15 \%)$. 
$11 \%$ in age group of $51-60 \%$ and $3 \%$ each in the age group of $61-70 \%$ years and $>70$ years. Among all cases $57 \%$ males and $43 \%$ were females (ratio 1.32:1). out of total cases: $69 \%$ were of generalized tonic clinic seizures (M 42, F 27) 7\% (M6, F1) status epileptics, (M2, F1) 03\% complex partial seizures, 6\% simple partial seizures \& $15 \%(\mathrm{M} 8, \mathrm{~F} 7)$ were of partial seizures with secondary generalization.

- From out of total number of cases (100), $85 \%$ had some etiological factor $15 \%$ cases were idiopathic were no etiological factor were found. Among 85 cases with known etiological factors, 36 were with neuro infections, 23 of CVA, 7 of metabolic cause, 51 of tumor, 4 organo phosphate compound poisoning, 3 cases of eclampsia and 7 cases with miscellaneous group. Although among neuro infection groups the commonest cause was neurocysticercosis $(37.33 \%)$ followed by meningitis $(27.77 \%)$. While among neuro infections with meningitis group tuberculosis was commonest followed by viral, cryptococcal \& meningococcal; malaria, neurocysticercosis etc.

- Incidence of neuro infections was more in males than female cases while among CVA group the female exceeded. There were total 4 cases of OP poisoning \& all females. Pregnancy related cases accounted for $13 \%$ of total

- The main clinical manifestations were in the form of loss of consciousness, involuntary movements, headache, frothing from mouth, postictal confusion, tongue bite \& incontinence. EEG record was abnormal in only 35\% (35 cases ) and normal in 65 cases. Neuro imaging (CT/MRI brain) was abnormal in $75 \%$ (75 cases) \& normal in 25 cases. In younger age groups the incidence of GTCS (generalized tonic-clinic seizures) was maximum with progressive decline in advancing age groups while percentage of partial seizures with secondary generalization was on increasing side with age advancement. In GTCS the EEG was reported normal in $69.57 \%$ of cases while abnormal in only $30.43 \%$. while in focal seizures (like in simple partial seizures \& complex partial seizures and with secondary generalization) the abnormal EEG reporting was much higher.

- Over all neuroimaging was reported abnormal in $75 \%$ of all cases. However it was found abnormal only in $65.22 \%$ of cases of GTCS while it was found abnormal in $100 \%$ cases of CPS SPS \& PSSG.

- Among there cases where neuro imaging (CT/MRI) was found abnormal the EEG was found abnormal only in $44 \%$ while in those cases where neuro imaging was found normal the EEG was reported abnormal in $8 \%$ cases.

\section{Discussion}

Seizures are common disorders found all over world with varying manifestations of seizures and etiologies which differ from region to region. In our study the males comprised of $57 \%$ while females $43 \%$. The onset of seizures in majority of patients was in young age group (51\% in 21 to 30 years age groups) while only $6 \%$ in the age group of more than 60 years. The etiological spectrum of seizures in different age group was significantly different in our study. In $3^{\text {rd }}$ decade, the neuro infection was the commonest cause of seizures, followed by CVA while in age group of 51-60 years, the space occupying lesions (tumor) \& CVA was commonest. In 61-70 years age groups the metabolic causes followed by CVA were common.

Overall incidence of GTCS was commonest (69\%) followed by PSSG (partial seizures with secondary generalization) in $15 \%$, SE (status epileptics) in $7 \%$, simple partial seizures in $6 \%$ \& complex partial seizures (CPS) in $3 \%$. Neuro infection was the leading cause of seizures (36\% of all cases) followed by CVA in $23 \%$, metabolic $7 \%$, eclampsia 3\%, space occupying lesion (tumor) 5\%, organophosphate poisoning in $4 \%$, miscellaneous $7 \%$ \& $15 \%$ cases were idiopathic. Neuro imaging \& EEG: the neuro imaging (CT/MRI brain) was found abnormal in $65.22 \%$ cases of GTCS while it was abnormal in all $100 \%$ cases of focal seizures (SPS, CPS \& PSSG). While EEG was found abnormal only in $35 \%$ of cases. In those remaining $65 \%$ cases of normal EEG, the neuro imaging was yet abnormal in $64.61 \%$ of these cases. Thus neuro imaging was more sensitive \& diagnostic in higher number of cases of seizures.

Tables \& Graphs:

\begin{tabular}{|c|c|c|c|c|c|c|}
\hline \multicolumn{7}{|c|}{ Age and Sex Distribution } \\
\hline \multirow[t]{2}{*}{ Age } & \multicolumn{2}{|r|}{ Male } & \multicolumn{2}{|r|}{ Female } & \multicolumn{2}{|r|}{ Total } \\
\hline & No. & $\%$ & No. & $\%$ & No. & $\%$ \\
\hline 21-30 & 25 & 43.86 & 26 & 60.47 & 51 & 51 \\
\hline $31-40$ & 10 & 17.54 & 5 & 11.63 & 15 & 15 \\
\hline 41-50 & 11 & 19.30 & 6 & 13.95 & 17 & 17 \\
\hline 51-60 & 7 & 12.28 & 4 & 9.30 & 11 & 11 \\
\hline 61-70 & 2 & 3.51 & $\mathbf{1}$ & 2.33 & 3 & 3 \\
\hline$>70$ & 2 & 3.51 & 1 & 2.33 & 3 & 3 \\
\hline Total & 57 & 100.00 & 43 & 100.00 & 100 & 100.00 \\
\hline Mean \pm SD & \multicolumn{2}{|c|}{$37.4 \pm 13.58$} & \multicolumn{2}{|c|}{$33.72 \pm 13.00$} & \multicolumn{2}{|c|}{$35.82 \pm 13.39$} \\
\hline
\end{tabular}




\begin{tabular}{|l|l|l|}
\hline \multicolumn{3}{|c|}{ Various types of CNS Tuberculosis in Patients with Seizures } \\
\hline CNS Tuberculosis (N=8) & No. & $\%$ \\
\hline Meningitis & 4 & 50.00 \\
\hline Tuberculoma & 2 & 25.00 \\
\hline Meningoencephalitis & 2 & 25.00 \\
\hline
\end{tabular}

\begin{tabular}{|l|c|c|c|c|c|c|}
\hline \multicolumn{7}{|c|}{ Association for Etiology and Types of Seizures } \\
\hline \multirow{7}{*}{ Etiology } & \multicolumn{7}{c|}{ Types of Seizure } & \multirow{2}{*}{ Total } \\
\cline { 2 - 7 } & GTCS & SE & PSSG & SPS & CPS & \\
\hline CVA & 12 & 0 & 9 & 2 & 0 & 23 \\
\hline Eclampsia & 2 & 1 & 0 & 0 & 0 & 3 \\
\hline Idiopathic & 14 & 1 & 0 & 0 & 0 & 15 \\
\hline Metabolic & 5 & 0 & 1 & 1 & 0 & 7 \\
\hline Miscellaneous & 4 & 1 & 0 & 0 & 2 & 7 \\
\hline Neuro-infection & 28 & 3 & 2 & 3 & 0 & 36 \\
\hline OP Poisoning & 3 & 1 & 0 & 0 & 0 & 4 \\
\hline Tumor & 1 & 0 & 3 & 0 & 1 & 5 \\
\hline Total & 69 & 7 & 15 & 6 & 3 & 100 \\
\hline
\end{tabular}

Chi Square $=60.774$ with 28 degrees of freedom, $p<0.001$

\begin{tabular}{|c|c|c|c|c|c|}
\hline \multicolumn{6}{|c|}{ Correlation of CT Scan/MRI Findings with Type of Seizures } \\
\hline \multirow{3}{*}{ Type of Seizures } & \multicolumn{4}{|c|}{ CT Scan/MRI } & \multirow{3}{*}{ Total } \\
\hline & \multicolumn{2}{|c|}{ Abnormal } & \multicolumn{2}{|c|}{ Normal } & \\
\hline & No. & $\%$ & No. & $\%$ & \\
\hline GTCS & 45.00 & 65.22 & 24.00 & 34.78 & 69.00 \\
\hline SE & 6.00 & 85.71 & 1.00 & 14.29 & $\mathbf{7 . 0 0}$ \\
\hline PSSG & 15.00 & 100.00 & $\mathbf{0 . 0 0}$ & $\mathbf{0 . 0 0}$ & 15.00 \\
\hline SPS & 6.00 & 100.00 & 0.00 & 0.00 & 6.00 \\
\hline CPS & 3.00 & 100.00 & 0.00 & 0.00 & 3.00 \\
\hline Total & 75.00 & 75.00 & 25.00 & 25.00 & 100.00 \\
\hline
\end{tabular}

Chi-square $=11.950$ with 4 degrees of freedom; $P=0.018$.

\begin{tabular}{|c|c|c|c|c|c|c|}
\hline \multicolumn{7}{|c|}{ Correlation of EEG And CT Scan Findings } \\
\hline \multirow{3}{*}{\multicolumn{2}{|c|}{ CT Scan / MRI }} & \multirow{2}{*}{\multicolumn{2}{|c|}{ Abnormal }} & \multirow{2}{*}{\multicolumn{2}{|c|}{ Normal }} & \multirow[b]{3}{*}{ Total } \\
\hline & & & & & & \\
\hline & & No. & $\%$ & No. & $\%$ & \\
\hline Abnormal & & 33 & 44 & 42 & 56 & $\mathbf{7 5}$ \\
\hline Normal & & 2 & 8 & 23 & 92 & 25 \\
\hline \multirow{2}{*}{\multicolumn{2}{|c|}{ Total }} & 35 & 35 & 65 & 65 & 100 \\
\hline & & \multicolumn{5}{|c|}{ fischer exact test $\mathbf{P}=0.001$} \\
\hline \multicolumn{7}{|c|}{ Distribution of Etiologies in Patients with Seizures } \\
\hline Etiology & Etiology & & & & No. & $\%$ \\
\hline \multirow[t]{6}{*}{ Neuro Infection } & & & & & 36 & 36 \\
\hline & Cerebra & Malaria & & & 7 & 7 \\
\hline & Meningi & & & & 10 & 10 \\
\hline & Mening & icephalitis & & & 5 & 5 \\
\hline & NCC & & & & 12 & 12 \\
\hline & Tubercu & ma & & & 2 & 2 \\
\hline \multirow[t]{5}{*}{ CVA } & & & & & 23 & 23 \\
\hline & CVT & & & & 10 & 10 \\
\hline & ICB & & & & 4 & 4 \\
\hline & Infarct & & & & 7 & 7 \\
\hline & SDH & & & & 2 & 2 \\
\hline Idiopathic & & & & & 15 & 15 \\
\hline \multirow[t]{6}{*}{ Metabolic } & & & & & 7 & 7 \\
\hline & Hypergl & emia & & & 1 & 1 \\
\hline & Hypogly & mia & & & 1 & 1 \\
\hline & Hypona & mia & & & 2 & 2 \\
\hline & Insulin / & poglycemi & & & 2 & 2 \\
\hline & Quinine & poglycem & & & 1 & 1 \\
\hline \multirow[t]{4}{*}{ Tumor } & & & & & 5 & 5 \\
\hline & Glioma & & & & 2 & 2 \\
\hline & Meningi & & & & 1 & 1 \\
\hline & Seconda & & & & 1 & 1 \\
\hline
\end{tabular}




\begin{tabular}{|l|l|r|r|} 
& GM & 1 & 1 \\
\hline \multirow{4}{*}{ Miscellaneous } & & 7 & 7 \\
\cline { 2 - 4 } & Alcohol Withdrawl & 3 & 3 \\
\cline { 2 - 4 } & AV Malformation & $\mathbf{3}$ & $\mathbf{3}$ \\
\cline { 2 - 4 } & Post Dialysis & $\mathbf{1}$ & $\mathbf{1}$ \\
\hline OP Poisoning & & $\mathbf{4}$ & $\mathbf{4}$ \\
\hline Eclampsia & & $\mathbf{3}$ & $\mathbf{3}$ \\
\hline Total & & $\mathbf{1 0 0}$ & $\mathbf{1 0 0}$ \\
\hline
\end{tabular}

\begin{tabular}{|c|c|c|c|c|c|c|c|}
\hline \multicolumn{8}{|c|}{ Association of Type of Seizure with Age Group } \\
\hline \multirow[b]{2}{*}{ Type of Seizure } & \multicolumn{6}{|c|}{ Age Group } & \multirow[b]{2}{*}{ Total } \\
\hline & 21-30 & $31-40$ & $41-50$ & $51-60$ & $61-70$ & $>70$ & \\
\hline GTCS & 37 & 9 & 12 & 6 & 3 & 2 & 69 \\
\hline SE & 4 & 1 & 2 & $\mathbf{0}$ & $\mathbf{0}$ & $\mathbf{0}$ & 7 \\
\hline PSSG & 6 & 3 & 2 & 3 & $\mathbf{0}$ & 1 & 15 \\
\hline SPS & 2 & 2 & 1 & 1 & 0 & 0 & 3 \\
\hline CPS & 2 & 0 & 0 & 1 & 0 & 0 & 3 \\
\hline Total & 51 & 15 & 17 & 11 & 3 & 3 & 100 \\
\hline
\end{tabular}
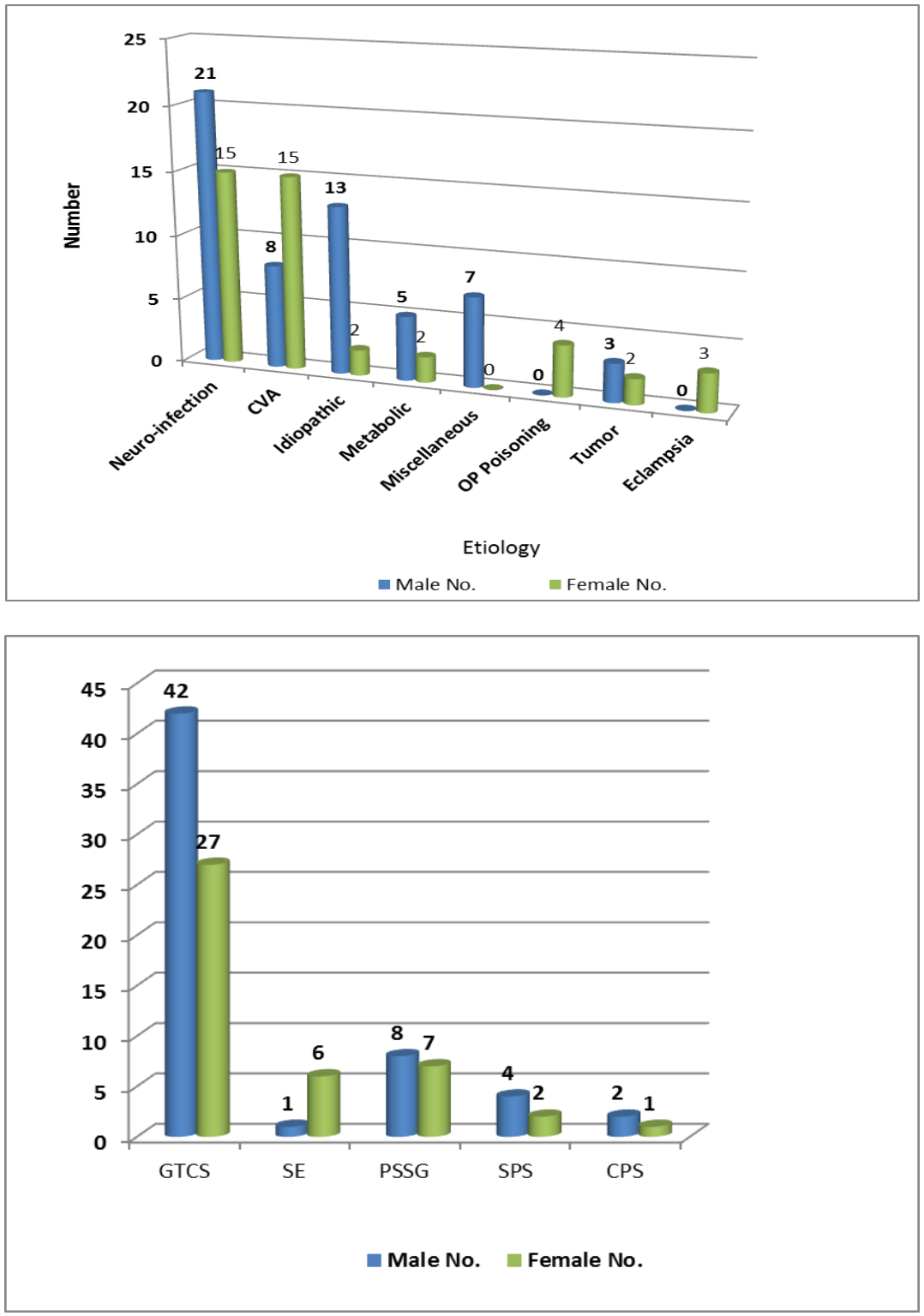


\section{Bibliography}

[1]. Lourdes V, Linda M . Seizure Disorders in Elderly. Am Fam Physician.

a. 2003;67:325:-32

[2]. Murthy JMK, Yangala R. AcuteSymptomatic seizures incidence and etiological spectrum: a hospital based study from south India . Seizure 1999;8:162-65.

[3]. Gibbs FA, Lennox WG, Gibbs EL. The electroencephalogram in diagnosis and localization of epileptic seizures. Arch Neurol Psychiatry. 1936;36:1225-35.

[4]. Sieveking EH . Analysis of 52 cases of epilepsy observed by rthe author. Lancet. 1857;527-8.

[5]. Giroud M, Gras P, Fayolle H. Early seizures after acute stroke. A study of 1640 cases . Epilepsa. 1994;35:959-64.

[6]. Dhanuka AK, Misra UK, Kalita J. Seizures after stroke a prospective clinical study. Nurol India 2001; 49:33-36.

[7]. DeToledo JC, Changing presentations of seizures with ageing: clinical and etiological factors. Gerontology. 1999;45:329-35.

[8]. Kevin HR, Sharon MH, Richard LB. Prospective Study of seizures in the Elderly in the Marshfield Epidemologic Study area (MESA). Epilepsia. 2001;42(12):1594-99.

[9]. Lubarsky SL, Barton JR, Friedman SA. Late postpartum eclampsia revisited. Obstet Gynecol. 1994;83 : 502-5.

[10]. Sendil, ArunN Kumar, Mohan V Kumar. "Late Onset Shake-Etiology at Stake-A Prospective Study". Int J Sci Stud. 2014;2(1):2024.

[11]. Murlidhar V, Venugopal K, New onset Seizure; Etiology and correlation of clinical features with computerized tomography and electroence phalography. J Sci. Soc. 2015;42(2):82-7

[12]. Wallace JC. Radionuclide brain scanning in investigation of late-onset seizures. Lancet. 1974;2:1467-70.

[13]. Young AC, Mohr PO, Forbes WS. Is routine computerized axial tomography in epilepsy worthwhile. Lancet. 1982;8:1336-1448. 